\title{
Immunological responses of HIVIAIDS patients treated with Nevirapine versus Efavirenz based highly active anti-retroviral therapy in Addis Ababa, Ethiopia: A retrospective cohort study
}

\author{
Zemedu Mehamed Tirfe ${ }^{1 \#}$, Tekabe Abdosh Ahmed ${ }^{2 \#}$, Negga Baraki Tedla ${ }^{3}$, \\ Mesfin Kote Debere ${ }^{1}$, Andamlak Gizaw Alamdo ${ }^{4}$

\footnotetext{
${ }^{1}$ Department of Epidemiology and Biostatistics, College of Medicine and Health Sciences, Arba Minch University, Arba Minch, Ethiopia; ${ }^{\#}$ Corresponding Author: zemedumohamed@yahoo.com, zemedu2003@gmail.com, messi.kid@gmail.com

${ }^{2}$ Schools of Medicine, College of Medicine and Health Sciences, Haramaya University, Harar, Ethiopia;

\#Corresponding Author: tekaba321@yahoo.com

${ }^{3}$ Department of Environmental Health Sciences, College of Medicine and Health Sciences, Haramaya University, Harar, Ethiopia
} \\ ${ }^{4}$ Arba Minch College of Health Sciences, Arba Minch, Ethiopia; gizandal@gmail.com
}

Received 8 May 2013; revised 8 June 2013; accepted 15 July 2013

Copyright (C) 2013 Zemedu Mehamed Tirfe et al. This is an open access article distributed under the Creative Commons Attribution License, which permits unrestricted use, distribution, and reproduction in any medium, provided the original work is properly cited.

\section{ABSTRACT}

Background: There are two approved non-nucleoside reverse transcriptase inhibitor antiretroviral drugs; namely Nevirapine (NVP) and Efavirenz (EFV). Nevirapine and EFV have comparable clinical efficacy when administered in combination regimens. But there is a lack of recent evidence showing the effect of NVP and EFV-based ARTs on immunological responses in HIV infected individuals in Ethiopia in general and Addis Ababa in particular. Methods: Retrospective cohort study design was used to compare immunological response rate of NVP and EFV based HAART regimen in Addis Ababa. Four hundred ninety two HIV infected patients who started HAART in ten selected health facilities were included in the study. Rate of immunologic response was examined at the $6^{\text {th }}, 12^{\text {th }}, 18^{\text {th }}$, and $24^{\text {th }}$ months of follow-up period. The time required to get immunological response was analyzed by Kaplan-Meier survival curve. Adjusted hazard ratio was calculated with a $95 \%$ confidence interval by Cox proportional hazards model to determine the rate of immunological response. To ascertain the association, bivariate and multi variable Cox proportional hazard model was used. Statistical significance was considered with two sides P-value of 0.05 . Results: The mean CD4

\footnotetext{
"The authors declare that they have no competing interests.
}

count ranged between $132.2 \mathrm{cell} / \mu \mathrm{l}$ at baseline and $302.3 \mathrm{cell} / \mathrm{\mu l}$ at the end of the follow-up period. This change was significant at $95 \%$ of $\mathrm{Cl}$ but did not show significant differences among the comparison group. The median time to get immunological response was 18 (75\% percental 12$)$ months. At the end of the follow-up period, $73.2 \%$ (76.6\% for NVP and $69.8 \%$ for EVF P-value 0.13 ) of the study population had immunological response. Conclusion: As a conclusion, there was a robust and sustained CD4 response and the effect of NVP and EFV based ART on change of mean CD4 count and immunological response was comparable and effective. Initiation of ART with high baseline CD4 count, in combination of IPT and with either NVP or EFV based NNTI was recommended.

Keywords: Efavirenz; Nevirapine; Immunological Response Rate; Mean CD4 Count

\section{BACKGROUND}

HIV remains a global health problem of unprecedented dimensions. According to the Joint United Nations Program on HIV/AIDS (UNAIDS) report, around 30.8 million adults and 3.4 million children were living with $\mathrm{HIV}$ at the end of 2010. In response to the epidemic, tremendous efforts have been done to control the infection starting from the first HIV case. This effort includes the development of antiretroviral (ARV) drugs [1]. The pri- 
mary goal of Highly Active Anti-Retroviral Therapy (HAART) is to prolong life, reduce HIV related mortality and morbidity in people living with HIV/AIDS. About 6.6 million people including 420,000 children were receiving antiretroviral therapy (ART) in low- and middleincome countries at the end of 2010. In the same year, 1.4 million people started lifesaving treatment; more than any year before [1].

More than 20 ARV compounds are now approved for use in US and Europe. But to date only two treatment strategies are recommended: 3 - 5 a backbone of two nucleoside analogues plus a non-nucleoside reverse transcriptase inhibitor (NNRTI) or protease inhibitor (PI). There are two approved NNRTIs named as Efavirenz (EFV) and Nevirapine (NVP). The question here is which of the combination is preferable. Currently there is no consensus on which NNRTI is the most effective in the treatment of HIV infection. For example, the US Department of Health and Human Services and British HIV Association Treatment Guidelines list EFV as the preferred agent over NVP. On the other hand, the WHO in 2010 revised ART guidelines, suggesting either NVP or EFV treat HIV-infected individuals [2-6]. But there is a lack of recent evidence showing effect of NVP or EFV-based HAART on immunological responses in HIV infected individuals in Ethiopia in general and Addis Ababa in particular. This study will fill the gap by assessing the immunological responses rate of HIV/AIDS patients treated with Nevirapine versus Efavirenz based HAART in Addis Ababa, July 1, 2009 - Dec. 31, 2011.

\section{METHODS}

\subsection{Study Area}

Addis Ababa has the status of both a city and a state. It is where the African Union and its predecessor Organization of Africa Union are based. The city often referred as "the political capital of Africa", due to its historical, diplomatic and political significance for the continent (Ethiopia Tourism Organization, 2010; Wikipedia, 2010). Addis Ababa Health Bureau is responsible organ for health care services in the city. There are 10 Sub-City Health Offices, which are directly accountable to their respective Sub-City Administrations. In 2011, there are 38 hospitals, 27 Health Centres and 87 private clinics in the city. The potential health service coverage in Addis Ababa with regard to geographical accessibility is $100 \%$ (Addis Ababa city Administration, 2008; Addis A. personal communication August, 2011).

The study followed adult HIV patients (age $\geq 15$ years) who started HAART between June 31 and Dec. 31, 2009 in ten selected health facilities of Addis Ababa. The cohort groups were followed for 24 months (July 1, 2009 Dec. 31,2011 ) for immunological response. Health facil- ity based retrospective fixed cohort study design was used to compare immunological responses of EFV and NVP based HAART regimen patients. The primary outcome measures of this study are the rate of immunological response (an increase of CD4 cell count by $\geq 50$ cells $/ \mu 1$ over the baseline value) and time to increasing CD4 cell count by 50 cells/ $\mu 1$. A CD4 count obtained in the nearest 6 months before the follow up period was taken as baseline value. About 1245 medical records of ART patients initiating HAART between $31^{\text {st }}$ June and $31^{\text {st }}$ Dec. 2009 were abstracted to select eligible patients in ten selected health facilities. Among this 602(49.95\%) were excluded from this study for five different reasons. One hundred and nineteen eight (32.89\%) were excluded due to the presences of active TB during initiation of ART, $137(22.75 \%)$ were pregnant mothers, $127(21.1 \%)$ didn't had data for baseline CD4 count, 103(17.1\%) had age less than 15 year and the remaining $37(16.14 \%$ ) were excluded due to treatment substitution to second line regimen before the first 6 months after initiation of ART.

\subsection{Sample Size Calculation}

Sample size was determined based on the assumption of $95 \%$ two sided confidences level, $90 \%$ power, percent of Unexposed with outcome $46 \%$, percent of exposed with outcome $62 \%, 10 \%$ lost to follow effect and 1:1 ratio of exposed to non-exposed. To get value of variables necessary for the sample size calculation, a pilot study was conducted in three health facilities which were not included in the main research. Based on the above assumption the final sample size was 492 .

\subsection{Data Collection}

Ethical Approval was granted by the Institutional Research Ethics Review Committee (IRERC) of Haramaya University and Addis Ababa City Administration Health Bureau Ethical Clearances Committee. A written consent form was signed by each health institution leader. Consent from patients was not obtained since this work used data from medical records of patients. A Structured data collection format was used to retrieve relevant data from medical records of patients by trained data collectors. The data collection forms were reviewed for completeness and accuracy. Information collected included sex, age at initiation of ART, marital status, educational status, occupation, prophylaxis, WHO stage, eligibility criteria, weight $(\mathrm{kg})$, height (meter), TB status, functional status and NRTI treatment substitution.

\subsection{Statistical Methods}

Data was entered to the computer by using EPI INFO Version 3.5.1. Then it was exported to SPSS for windows version 16.0 for analysis. For comparison of treatment groups EFV group was selected as references (non-ex- 
posed) group. Rate of immunological response was examined at $6,12,18$, and 24 months after initiation of ART. The time required to increasing CD4 count by 50 cells/ $\mu$ l was analyzed by Kaplan-Meier estimation. Logrank test was used to compare the two groups. Hazard ratio was calculated with a $95 \%$ confidence interval by Cox proportional hazards model to determine rate of immunological response. To ascertain the association; variables found to be significant $(\mathrm{p}<0.2)$ in a bivariate analysis were used to build a multi variable model. For multi variable analysis statistical significance was considered with two sides P-value of 0.05 .

\section{RESULTS}

\subsection{Background Information}

All patients were followed retrospectively for a complete of 24 months (two years) but for different reasons, study participants retained in the cohort for different length of follow up time: they stayed for a minimum of four, maximum of twenty four and median of eighteen $(\mathrm{IQR}=12)$ months. Concerning to follow up condition, $429(87.2 \%)$ complete follow up, $19(3.9 \%)$ died within the follow up period, $24(4.9 \%)$ lost to follow up, 11(2.2) transfer out from follow up site and $9(1.8 \%)$ substitute their original treatment regimen to other NNRTIs or to second line regimen. The follow up status didn't have statistically significant difference (P-value 0.869) among exposed and non-exposed groups.

\subsection{Socio-Demographic Variables}

The median age of the study participants was 34 year (IQR, 10.75). Majority 289(58.7\%) of the study subjects were females. Among these 147 (50.9\%) took NVP based ART. More than half of $(319,64.8 \%)$ the study participants were Orthodox by religion. The remaining $86(17.5 \%)$ and $87(17.7 \%)$ patients belong to Muslim and Protestant respectively. Regarding to educational status, $53(10.8 \%)$ of the study subject had tertiary level education; whereas $168(34.1 \%)$ and $178(36.2 \%)$ complete secondary and primary education respectively. The remaining 93(18.9\%) patients had no educational history. Concerning to occupational status, $81(16.5 \%)$ were governmental employers whereas only $31(6.3 \%)$ did not have work and the rest $371(77.2 \%)$ involved in different income generating activities. Except educational status and occupational status all other socio-demographic variables did not had significant difference among exposed and non-exposed group (Table 1).

\subsection{Clinical Characteristics of Patients at Art Initiation}

When we see the type of starting NRTIs regimen the
Table 1. Socio-demographic status of HIV/AIDS patients treated with NVP versus EFV based HAART in A. A July 1, 2009 Dec. 31, 2011.

\begin{tabular}{|c|c|c|c|c|}
\hline \multirow{2}{*}{\multicolumn{2}{|c|}{ Variables }} & \multicolumn{2}{|c|}{ Exposure Status $(n=492)$} & \multirow[b]{2}{*}{ P-Value } \\
\hline & & $\begin{array}{l}\text { Nevirapine } \\
(\mathrm{n}=246)\end{array}$ & $\begin{array}{l}\text { Efavirenz } \\
(\mathrm{n}=246)\end{array}$ & \\
\hline \multirow{2}{*}{ Sex } & Male & $99(48.8)$ & $104(51.2)$ & \multirow{2}{*}{0.714} \\
\hline & Female (\%) & $147(50.9)$ & $142(49.1)$ & \\
\hline \multirow{2}{*}{ Age } & Median & 33 & 35 & \multirow{2}{*}{$0.071^{*}$} \\
\hline & Interquartile Range & 11 & 10 & \\
\hline \multirow{4}{*}{ Marital Status } & Single $(\%)$ & $93(52.2)$ & $85(47.8)$ & \multirow{4}{*}{0.688} \\
\hline & Married & 193(47) & $132(53)$ & \\
\hline & Divorced & $27(56.2)$ & $21(43.8)$ & \\
\hline & Widowed & $9(52.9)$ & $8(47.1)$ & \\
\hline \multirow{4}{*}{$\begin{array}{l}\text { Educational } \\
\text { Status }\end{array}$} & No Education (\%) & $36(38.7)$ & $57(61.3)$ & \multirow{5}{*}{0.025} \\
\hline & Primary & $105(57.9)$ & $75(42.1)$ & \\
\hline & Secondary & $81(48.2)$ & $87(51.8)$ & \\
\hline & Tertiary & $26(49.1)$ & $27(50.9)$ & \\
\hline \multirow{3}{*}{ Religion } & Muslim (\%) & $43(50.0)$ & $43(50.0)$ & \\
\hline & Orthodox & $161(50.5)$ & $158(49.5)$ & \multirow[t]{2}{*}{0.936} \\
\hline & Protestant & $42(48.3)$ & $45(51.7)$ & \\
\hline \multirow{9}{*}{$\begin{array}{l}\text { Occupational } \\
\text { Status }\end{array}$} & $\begin{array}{c}\text { Private Employee } \\
(\%)\end{array}$ & $27(39.1)$ & $42(60.9)$ & \\
\hline & Driver & $30(68.2)$ & $14(31.8)$ & \\
\hline & $\begin{array}{l}\text { Governmental } \\
\text { Employee }\end{array}$ & $36(44.4)$ & $45(55.6)$ & \\
\hline & Teacher & $31(43.1)$ & $41(56.9)$ & \\
\hline & Merchant & $42(56.0)$ & $33(44.0)$ & \\
\hline & House Wife & $22(44.0)$ & $28(56.0)$ & \\
\hline & Student & $25(62.5)$ & $15(37.5)$ & \\
\hline & Daily Laborer & $14(46.7)$ & $16(53.3)$ & \\
\hline & Not Employ & $19(61.3)$ & $12(38.7)$ & 0.025 \\
\hline
\end{tabular}

${ }^{*}(\mathrm{Df}=490, \mathrm{f}=2.285)$.

highest proportion 360(73.2\%) have started with Zidovudine regimen followed by $94(19.1 \%)$ Stavudine and $38(7.7 \%)$ Tenofovir based regimen. Among those who started with Tenofovir based regimen 34(89.3\%) were from EFV group. From those who initiated with Zidovudine 194(53.9\%) and from Stavudine 48 (51.1\%) were from NVP group. The median week to start HAART after confirmation of HIV infection was $8.5(\mathrm{IQR}=38)$ in overall study subjects and $9(\mathrm{IQR}=37)$ for NVP arms. Lower value $(8, \mathrm{IQR}=42)$ was detected among EFV group but the difference was not significant $(\mathrm{P}$ value 0.513) among the cohort groups.

All variables of clinical characteristics of patients at ART initiation didn't show significant differences between the study groups at 5\% level of significance (for all variables comparison the $\mathrm{P}$-value was $>0.05$ ).

\subsection{Rate of Immunological Response}

Among those complete the study 314(73.2\%) patients' 
had immunological response within 24 months of follow up period. Of these $164(52.2 \%)$ were from the exposed group. The crude rate of immunological response didn't show significant difference within cohort groups (OR 1.42 (0.98 - 2.13), P-value 0.134). The largest proportion $98(31.2 \%)$ of study subjects got immunological response at 18 months of follow up period. The rate of immunological response at $6,12,18$ and 24 month was $12.9 \%$, $24.0 \%, 28.6 \%$ and 17.2 respectively. This trend had significant differences at $\mathrm{P}$ value of 0.012 . The rate of immunological response at 12,18 and 24 month was 2.13 , 2.69 and 1.4 times greater than the rate of 6 month. The incidences rate also didn't show significant differences among cohort groups at all comparison months (P-value $>0.05)$.

\subsection{Time Required for Immunological Response}

Fifty percent of the study population got immunological response on 18 (95\% CI 16.78 - 19.93) month of follow up period. The mean month required for the primary outcome was $17.38^{\text {th }}(95 \%$ CI $16.72-19.97)$ month. The mean and median month to get immunological response was 17.23 (95\% CI of $16.36-18.12)$ and 18.0 (95\% CI 16.45 - 19.55) month respectively for NVP group. But for EFV group it was 17.45 (95\% CI 16.56 - 18.33) and 18.0 (95\% CI 16.07 - 19.92) respectively. By logrank test the time period to get immunological response among the cohort group didn't show statistical significance differences with $\mathrm{P}$ value of 0.28 .

\subsection{Factors Associated with Immunological Response}

As shown on Table 2 only four baseline variables have showed significant association with immunological response at a $5 \%$ level of significance by bivariate analysis of Cox-proportional hazard regression. By this analysis variables such as health facility type, marital status (Divorced), religion (Orthodox), eligibility criteria, starting NRTI and WHO clinical stage were significant at $\mathrm{P}$ value of less than 0.2. Therefore, these variables were retained for multi variable analysis in addition to the above four variables.

The selected twelve variables were entered to multi variable analysis to further evaluation and to control the effect of confounder on the truth value. Forward LR Cox regression model was used by taking in account all assumption of the model for the fitness of the variable to the model.

At the end, only five variables were significant at 5\% level of significance. Based on this result females were 1.374 (95\% CI AHR 1.01 - 1.63, P value 0.048) times more likely to have immunological response compared to
Table 2. Factors determining immunological response of HAART patients in A.A, July 1, 2009 - Dec. 31, 2011.

\begin{tabular}{|c|c|c|c|c|c|}
\hline \multicolumn{2}{|c|}{ Variables } & \multirow{2}{*}{$\begin{array}{c}\text { CHR } \\
1.05\end{array}$} & \multirow{2}{*}{$\begin{array}{c}\text { P-Value } \\
0.360\end{array}$} & \multirow{2}{*}{$\begin{array}{c}\text { AHR } \\
(95 \% \mathrm{CI})\end{array}$} & \multirow[t]{2}{*}{ P-Value } \\
\hline Exposure & Nevirapine & & & & \\
\hline Status & Efavirenz & 1.00 & & & \\
\hline \multirow{3}{*}{$\begin{array}{l}\text { Facility } \\
\text { Type }\end{array}$} & Governmental & 0.84 & 0.166 & 0.8 & 0.142 \\
\hline & Private & 1 & & 1 & \\
\hline & $<24$ Year & 1 & & & \\
\hline \multirow[t]{2}{*}{ Age } & 25 - 45 Year & 1.01 & 0.934 & & \\
\hline & $>45$ Year & 1.03 & 0.776 & & \\
\hline \multirow{3}{*}{ Sex } & Female & 1.44 & 0.002 & 1.37 & 0.048 \\
\hline & Male & 1 & & 1 & \\
\hline & Single & 1 & & 1 & \\
\hline \multirow{4}{*}{$\begin{array}{l}\text { Marital } \\
\text { Status }\end{array}$} & Married & 0.70 & 0.190 & 0.95 & 0.668 \\
\hline & Divorced & 0.63 & 0.084 & 1.15 & 0.497 \\
\hline & Widowed & 0.78 & 0.418 & 1.31 & 0.350 \\
\hline & No Education & 1 & & 1 & \\
\hline \multirow{4}{*}{$\begin{array}{l}\text { Educational } \\
\text { Status }\end{array}$} & Primary & 1.11 & 0.519 & 1.10 & 0.569 \\
\hline & Secondary & 1.29 & 0.110 & 1.20 & 0.289 \\
\hline & Tertiary & 1.19 & 0.428 & 1.17 & 0.498 \\
\hline & Orthodox & 1.02 & 0.779 & 0.99 & 0.926 \\
\hline \multirow[t]{2}{*}{ Religion } & Muslim & 0.86 & 0.153 & 0.87 & 0.500 \\
\hline & Protestant & 1 & & 1 & \\
\hline \multirow{3}{*}{$\begin{array}{l}\text { Starting } \\
\text { NRTIs }\end{array}$} & Stavudine & $\begin{array}{l}0.004 \\
0.004\end{array}$ & 2.144 & 1.57 & 0.104 \\
\hline & Zidovudine & 0.016 & 1.884 & 1.30 & 0.304 \\
\hline & TDF & 0.016 & 1 & 1 & \\
\hline \multirow{2}{*}{$\begin{array}{l}\text { Presences } \\
\text { of OI }\end{array}$} & Yes & 0.98 & 0.876 & & \\
\hline & No & 1 & & & \\
\hline \multirow{3}{*}{$\begin{array}{l}\text { Eligible } \\
\text { Criteria }\end{array}$} & CD4 count & 0.83 & 0.136 & 0.71 & 0.005 \\
\hline & Clinical & 1 & & 1 & \\
\hline & Stage 1 & 1.38 & 0.219 & 1.49 & 0.049 \\
\hline \multirow{3}{*}{$\begin{array}{l}\text { WHO } \\
\text { Clinical } \\
\text { Stage }\end{array}$} & Stage 2 & 1.28 & 0.344 & 1.36 & 0.299 \\
\hline & Stage 3 & 0.94 & 0.816 & 1.04 & 0.887 \\
\hline & Stage 4 & 1 & & 1 & \\
\hline \multirow{4}{*}{$\begin{array}{c}\text { Functional } \\
\text { Status at } \\
\text { Baseline }\end{array}$} & Working & 0.90 & 0.656 & 0.86 & 0.579 \\
\hline & Ambulatory & 0.90 & 0.666 & 0.86 & 0.571 \\
\hline & Bedridden & 1 & 0.901 & 1 & \\
\hline & Under Weight & 1 & 0.215 & 1 & \\
\hline \multirow{3}{*}{$\begin{array}{l}\text { BMI at } \\
\text { Baseline }\end{array}$} & Normal & 0.94 & 0.601 & 1.01 & 0.938 \\
\hline & Over Weight & 1.08 & 0.695 & 1.06 & 0.771 \\
\hline & Obesity & 2.34 & 0.064 & 2.53 & 0.055 \\
\hline \multirow{2}{*}{$\begin{array}{l}\text { Provision } \\
\text { of IPT }\end{array}$} & Given & 1.31 & 0.021 & 1.37 & 0.012 \\
\hline & Not Given & 1 & & 1 & \\
\hline $\begin{array}{l}\text { Baseline } \\
\text { CD4 Count }\end{array}$ & & 0.996 & $0.000^{*}$ & $0.997 \checkmark$ & 0.000 \\
\hline
\end{tabular}

${ }^{*} \mathrm{~B}=-0.004 ; \checkmark \mathrm{B}=-0.005$.

male study participants. Patients those who have started ART based on their CD4 count were 0.71 (95\% CI 0.54 0.94 , $\mathrm{P}$ value 0.005 ) time less likely to got immunologi- 
cal response compared to those initiated based on their clinical status. Among the four different WHO clinical stages, stage I patients were $1.49(95 \%$ CI AHR 1.02 0.2 .68 ; P value 0.049 ) times more like to develop the outcome compared to stage four patients. But the other stages didn't show significant association at $\mathrm{P}$ value of 0.05 . When the effect of other variables controlled, taking INH preventive therapy also significantly associated with immunological response. Odd to develop the outcome among patients received the prophylaxis were 1.363 (95\% CI 1.07 - 1.74, $\mathrm{P}$ value 0.012 ) times higher compared to those didn't take the INH prophylaxis.

According to this study result those who developed immunological response had significantly high CD4 count at baseline compared to those who didn't get the immunological response. The baseline CD4 count also had negative interaction with immunological response. When the baseline CD 4 count decreased by 1 cells/ $\mu 1$ the risk to develop immunological response will be decreased by 0.005 .

\section{DISCUSSION}

At the end of follow up period $73.2 \%$ of the study population had immunological response. This rate was lower when compared to the result of retrospective cohort study conducted in France. According to that study the rate was $84.4 \%$ among viral load $(\mathrm{VL}) \leq 100,000$ copies $/ \mathrm{ml}$ and $85.8 \%$ among VL $\geq 100,000$ copies $/ \mathrm{ml}$. During the comparison of immunological response rate insignificant difference (P-value 0.134) was detected among the cohort groups. Even if it was not significant NVP groups were $1.425(0.925-2.185)$ times more likely to develop immunological response compared to EFV groups. This result also agreed with many studies conducted among different study population. In the finding of Volerie et al. study EFV (HR 1.08 P value > 0.05) has similar immunological efficacy with NVP. But this study included patient with CD4 count less than 200 cells $/ \mu$ l only [7]. Another prospective cohort study conducted in England on 2003 agreed with this result. According to this study result; by using EFV results as a reference, a nonsignificant (AHR 0.93, 95\% CI 0.67 - 1.29) trend was observed for NVP based regimens [8].

Like the above study, findings from retrospective cohort conducted among patients whose pre-treatment CD4 cell count was less than 100 cells/ $\mu \mathrm{l}$; NVP and EFV based HAART regimens were effective and comparable, in term of immunological responses. Those, received NVPbased regimen had about $40 \%$ (HR $=0.49,95 \%$ CI 0.22 $1.09, \mathrm{P} \geq 0.144$ ) lower chance of achieving immunological response than patients who received the EFV-based regimen [9]. A similar finding was observed in Meta-analysis conducted among seven clinical trials. The result of this review showed the absences of critical differences between EFV and NVP for immunological responses. Based on the five trials' data the immunological response was difference $(\mathrm{WMD}=-2.00 ; 95 \% \mathrm{CI}-23.17$ to 19.18 , $\mathrm{p}=0.92)$ in the EFV and NVP groups [10].

The median time to got immunological response was 18 (95\% CI 16.78 - 19.93) month. The incidences rate of immunological response at $6,12,18$ and 24 month was $12.9 \%, 24.0 \%, 28.6 \%$ and $17.2 \%$ respectively. This trend had significant differences at $\mathrm{P}$ value of 0.012 . Taking such amount of time to the outcome can be as result of the drug efficacy time or due to other patient related factors such as adherences status, body metabolism ability and initial immunity status. This finding can be affected due to classification of measurement periods to small number of categories. The duration for immunological response also didn't show significant differences ( $\mathrm{P}$ value of 0.28 ) among cohort groups at all comparison months. The mean month to got immunological response was $17.23(95 \%$ CI of $16.36-18.12)$ for NVP group but it was 17.45 (95\% CI 16.56 - 18.33) EFV group. There for it possible to conclude as the time required to the outcome was the same in the two cohort groups. The result can be affected by patient adherence status which was not assessed by this study.

According to this study result female sex, WHO clinical stage 1 and taking IPT were associated with faster immunological response ( $\mathrm{P}$ value $<0.05$ in all cases). This association also may be due to the patients' adherences status, presences of additional factor to enhance immunological status or due to absences of some OIs'. On this study, the two categories of NNRTI treatment regimen didn't show significant association at $5 \%$ of significant level. But on other two studies significant association was observed at P-value of 0.05 . According to Philps et al. study EFV was $0.5(0.4-0.63, \mathrm{P}<0.001)$ times lower to had immunological response compared to NVP. Similarly in Kamya et al. study NVP groups were 2.59 (1.2 $5.59, \mathrm{P}$ value 0.02 ) times higher to develop the outcome. In both of studies, NVP had a higher chance of immunological response compared to EFV arm. These differences may be as result of differences in follow up period. The follow up period for Kamya et al. and Philip et al. studies was 4 years which is longer than this study. In addition to this, variation in socio-demographic variable may lead to this discrepancy $[11,12]$.

According to this study sex was associated with the outcome of the study. The adjusted HR for sex was 1.276 $(1.002,1.625, \mathrm{P}$ value 0.048$)$ when females were compared to male. This finding was not agreed with the result of Moing et al. study. Based on that study males were at high risk to response to the treatment compared to female (P value 0.002$)$. In other studies $[9,11]$ significant association were not detected among sex and immunological response $[9,11,13]$. Variation can be as result of 
sample selection procedure. This study exclude pregnant women form the study population.

Regarding to Baseline CD4 count similar result was detected form many studies. Based on this study result decreasing the CD 4 count by 1 cells $/ \mu 1$ will decrease the rate of immunological response by 0.05 time $(\mathrm{P}=0.000)$. Suggestive result was obtained from Philps et al. (OR $0.9295 \% \mathrm{CI}, 0.4-0.97, \mathrm{P}<0.002)$ and Boulle et al. (OR93 95\% CI $0.98-1.01, \mathrm{P}=0.004$ ) studies. In both of the case low CD4 count value was associated with low risk of response $[12,14]$. Only from this study significant association was detected from WHO clinical stage and provision of IPT. Those who start ART with stage I had risk of outcome 1.49 (1.02 - 2.68; P value 0.049) times lower compared to stage IV patients. In addition to the true association the small sample size for comparison group can lead to this association. Provision of INH also contributes for immunological response. The adjusted hard odd ratio was 1.363 (95\% CI $1.071-1.735$, P value 0.012 ) for those received the prophylaxis. This can be as result of decreasing the rate of TB due to IPT.

\section{Limitations of the Study}

The study was limited by its retrospective design that involved analysis of secondary data. So, the researcher could not control for some of the confounding covariates such as adherences status, socio-economic variables, and other nutritional status indicator other than BMI. To have comparable study subjects at baseline TB patients and pregnant women were excluded from the study. This also may affect the true result because some important study subject related may be not included in the analysis.

\section{CONCLUSION}

There was a sustained and robust CD4 response and the effect of NVP and EFV on change of mean of CD4 count was the same. Similarly during the comparison of immunological response rate, insignificant difference was detected among the cohort groups. Fifty percent of the study participants got the expected immunological response at the $18^{\text {th }}$ month of the follow-up period. The required time for immunological response was the same in the two study groups. Being female, initiation of ART at WHO stage I, provision of IPT and high baseline CD4 count contributed to achieving the immunological response.

\section{Authors' Contributions}

ZM conceived the study, participated in the design and helped draft the manuscript. TA, NB, MK and AG participated in the design and helped draft the manuscript. All authors read and approved the final manuscript.

\section{ACKNOWLEDGEMENTS}

We would like to express our deepest gratitude to Addis Ababa City Administrative Health Bureau for their grate contribution to conduct this research. We also would like to thank Mr. Zelalem Birhanu and $\mathrm{Mr}$ Estifanos Yalew for their genuine co-operation and assistance. Last but not least our appreciation will go to our colleagues Fatimetu Mohammed, Mulatu Ayana and Wubante Taye for their unreserved support and encouragement.

\section{REFERENCES}

[1] UNAIDSAIDSat30 (2011) Nations at the crossroads. Geneva.

http://www.unaids.org/en/resources/unaidspublications/20 $11 />$

[2] Brian, G., Margaret, J., Jane, A., Saye, K., Abdel, B., Clifford, L., et al. (2008) British HIV association guidelines for the treatment of HIV-infected adults with ART. London.

[3] Daniel, P. and Elena, F. (2008) Initiating antiretroviral therapy in a treatment naive patient when and what to use? In: European Infectious Disease, HIV Unit DoID, University Hospital Bellvitge.

[4] Services DoHaH (2011) Panel on antiretroviral guidelines for adults and adolescents.

[5] Robert, M. (2009) Immunological and virological responses in highly active antiretroviral therapy naïve patients exposed to Isoniazid preventive therapy. University of South Africa.

[6] WHO (2010) Antiretroviral therapy for HIV infection in adults and adolescents recommendations for a public health approach. WHO, Geneva.

[7] Volerie, P., Davi Volerie, P., David, R., Saadia, F.M., Mokhtar, V., Chrsitina, P., et al. (2007) First line highly active antiretroviral therapy regimen in 2001-2002 in Frances hospital data base HIV combined prescription and biological outcome. International Medical Press, 12, 317 324.

[8] Stebbing, L.W., Jones, R., Michailidis, C., Sawleshwarkar, S., Mandalia, S., Bower, M., et al. (2004) A comparison of the CD4 response to antiretroviral regimens in patients commencing therapy with low CD4 counts. Journal of Antimicrobial Chemotherapy, 54, 503-507.

[9] Manosuthi, W., Sungkanuparph, S., Manosuthi, W., Sungkanuparph, S., Vibhagool, A., Rattanasiri, S., et al. (2004) Nevirapine-versus efavirenz-based highly active antiretroviral therapy regimens in antiretroviral-naive patients with advanced HIV infection H. HIV Medicine, 5, 105-109.

[10] Mbuagbaw, L.C.E., Irlam, J.H., Spaul Mbuagbaw, L.C.E., Irlam, J.H., Spaulding, A., Rutherford, G.W., et al. (2011) Efavirenz or nevirapine in three-drug combination therapy with two nucleoside-reverse transcriptase inhibitors for initial treatment of HIV infection in antiretroviral-naïve individuals (Review). The Cochrane Library, 4.

[11] Kamya, M., Mayanja-Kizza, H., Kambugu, A., BakeeraKitaka, S., Semitala, F. and Mwebaze-Songa, P. (2007) Predictors of long-term viral failure among Ugandan chil- 
dren and adults treated with antiretroviral therapy. Journal of Acquired Immune Deficiency Syndrome, 46, 187193.

[12] Naiel, N.K.P., Clinton, W. and Glenda, K. (2002) Comparison of Nevirapine and Efavirenz Containing Antiretroviral Regimens in Antiretroviral-Naïve Patients: A Cohort Study. HIV Clinical Trials, 3, 296-303.

[13] Moing, V.L., Thiebau, R., Chene, G., Sobel, A., Massip, P., Collin, F., et al. (2007) Long term evaluation of CD4 count in patient with plasma HIV RNA persistently $<500$ during treatment of antiretroviral therapy. HIV Medicine, 8, 156163.

[14] Boulle, A., Van Cutsem, G., Cohen, K., Hilderbrand, K., Mathee, S., Abraham, M., et al. (2008) Outcomes of nevirapine and efavirenz based antiretroviral therapy when coadministered with rifampicin-based antitubercular therapy. Journal of American Medical Association, 300, 530-539. 